\title{
BIOMIMETIC NANOCOMPOSITE STRUCTURES DESIGNED FOR COATING OF ORTHOPEDIC IMPLANTS: AFM INVESTIGATION
}

\author{
REKA BALINT ${ }^{a}$, IOAN PETEAN ${ }^{a}$, PETRE T. FRANGOPOL \& \\ AURORA MOCANU ${ }^{a}$, GEORGE ARGHIR $^{\mathrm{b}}$, SORIN RIGA $^{\mathrm{a}, \mathrm{c}}$, \\ GHEORGHE TOMOAIA ${ }^{c, d}$, OSSI HOROVITZ ${ }^{a}$, \\ MARIA TOMOAIA-COTISEL ${ }^{\mathrm{a}, \mathrm{c}^{*}}$
}

\begin{abstract}
Titanium implants are highly resistant to external forces and have affordable prices but the contact between $\mathrm{Ti}$ metal and surrounding native tissue could provoke an immunological response. The developing of biomimetic coating onto the $\mathrm{Ti}$ surface proves to be a smart choice to enhance the osseointegration and ensure an optimal healing process, due to the creation of nanostructured biomaterials like those in native bone. Thus, we designed a composite coating based on multi-substituted hydroxyapatite (noted ms-HAP or HAPc) nanoparticles, NPs, doped with essential elements: $\mathrm{Mg}, \mathrm{Zn}$ and $\mathrm{Si}$, functionalized with collagen type 1 (COL), embedded into poly lactic acid, PLA, matrix, and finally covered with COL layer to achieve biomimetic structures. Thin layers of biomimetic composite were self-assembled onto Ti surface via dip-coating method. Both, initial and coated Ti implants were investigated by atomic force microscopy (AFM), which allows surface investigation at high resolution of nano-level. COL amount in composite might self-assemble as COL fibers assuring a biomimetic structure, characterized by important features, like suitable porosity to facilitate the delivery of nutrients to osteoblasts and proper nano-topography and surface roughness to promote cell adhesion and proliferation. The outermost layer is of pure collagen which could assure a natural attachment to the bone tissue promoting osseo-integration.
\end{abstract}

Keywords: biomimetic structure, bio-composite, multi-substituted hydroxyapatite, collagen, PLA, AFM images, surface roughness

a Babeş-Bolyai University, Faculty of Chemistry and Chemical Engineering, Research Center of Physical Chemistry, 11 Arany Janos str., RO-400028, Cluj-Napoca, Romania

b Technical University of Cluj-Napoca, Faculty of Materials and Environment Engineering, 103-105 Muncii Boulevard, RO-400641, Cluj-Napoca, Romania

c Academy of Romanian Scientists, 3 Ilfov Str., RO-050044, Bucharest, Romania

d Iuliu Hatieganu University of Medicine and Pharmacy, Department of Orthopedics and Traumatology, 47 Gen. Traian Mosoiu Str., RO-400132, Cluj-Napoca, Romania

\& Deceased on December 11, 2020

* Corresponding author: mcotisel@gmail.com 
REKA BALINT, IOAN PETEAN, PETRE T. FRANGOPOL, AURORA MOCANU, GEORGE ARGHIR, SORIN RIGA, GHEORGHE TOMOAIA, OSSI HOROVITZ, MARIA TOMOAIA-COTISEL

\section{INTRODUCTION}

The body hard tissue trauma could affect mobility of the patients for long time, even if their life is not in danger. Some difficult cases lead to the patient's invalidity. Therefore, orthopedic research is focused on the improvement of bone trauma healing which often imply usage of nanobiomaterials as bone substitutes [1-10] and artificial implants [11-13].

The implants need to be strong enough and not so heavy to assure a good function of restored bone and to be biocompatible with the host tissue [14, 15]. The foreign body reaction occurs if the implant materials have a bad interaction with the native tissue $[16,17]$. It could generate local stress and possibly infection which may lead to the removal of the implant [17]. A possible solution for surpassing these drawbacks would be the developing of biomimetic structures similarly to those in natural healthy bone.

Metallic implants are easy to be worked into the desired shape, have great mechanic and wearing resistance but have a lower biocompatibility and often are heavier than common bone tissue. Also, they have lower production costs than other complex materials. Several alloys like special stainless steel [18-20] and titanium [21-23] prove to have good characteristics as mechanical resistance and weight and are inert enough in contact with living tissues. Despite these good characteristics the wounded bone has a long time of healing and needs to accept the implant. Therefore, it is important to increase the biocompatibility of the metallic surface of implants using different methods to avoid high increases of production costs.

The coating needs to contain several components of the natural bone such as collagen (COL) $[24,25]$ and hydroxyapatite (HAP) $[26,27]$ to assure a proper connection between implant and the native tissue. It is not enough to put COL and HAP into the coating layers on Ti implants to assure a biomimetic coating. A synergism between them is needed to generate a biomimetic coating with a similar structure to those of natural bone. The data in literature show that the most important fact to obtain a biomimetic coating is to use the HAP/COL ratio as in natural bone $[28,29]$ and to use a biocompatible polymer matrix which could be reticulate by the natural compounds [30, 31]. Polylactic acid (PLA) proves to be a biocompatible polymer which was successfully used into biomimetic composites implanted in vivo [32, 33].

Titanium is lighter than stainless steel assuring better mechanical properties and is further considered as target implant for developing biomimetic coatings for an improved osseointegration with natural bones. This purpose needs special investigation technique able to visualize the composite structure at finest details [34-36]. 
Atomic force microscopy (AFM) is one of the most powerful investigation methods of the composite surface within high resolution at nano-level [37-42]. In this work, the focus is on the application of nanotechnology in tissue engineering research highlighting nano-engineered composites designed to coat the Ti implants.

The goal of this work is related to developing innovative coatings, which can mimic the natural bone structure and reinforce in vivo tissue repair strategies [32]. In the last years, important advances in tissue engineering have been achieved, especially on usage of multi-substituted hydroxyapatites, ms-HAPs [32, 42, 43].

Thus, we designed a biomimetic composite coating based on multisubstituted HAP (noted ms-HAP or HAPc) nanoparticles, NPs, doped with essential elements: $\mathrm{Mg}, \mathrm{Zn}$ and $\mathrm{Si}$, functionalized with collagen type 1 (COL), embedded into poly lactic acid, PLA, matrix, and finally covered with COL layer achieving biomimetic structures, like ms-HAP/COL@PLA/COL.

\section{RESULTS AND DISCUSSION}

Ti rods were tested by X-ray diffraction (XRD), and the XRD pattern is shown in Figure 1. The obtained pattern evidences the diffraction peaks only for titanium proving the highest purity of Ti rods.

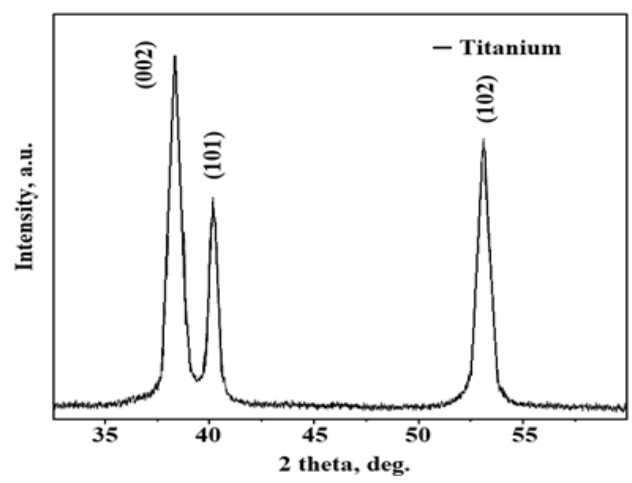

Figure 1. XRD patterns of the Ti rod with Miller indices in the brackets for diffracting planes.

The developed peaks are strong and intense corresponding to the crystalline state of $\mathrm{Ti}$ rods and diffracting planes corresponding to Miller indices (002), (101) and (102). 


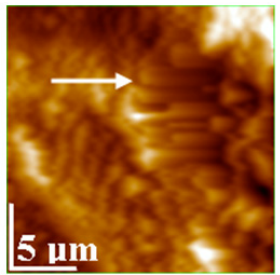

a

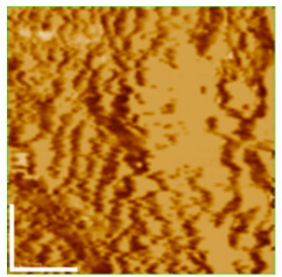

b

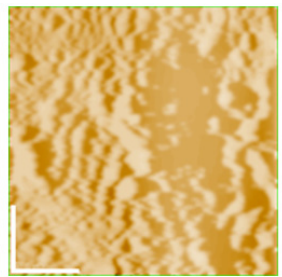

C
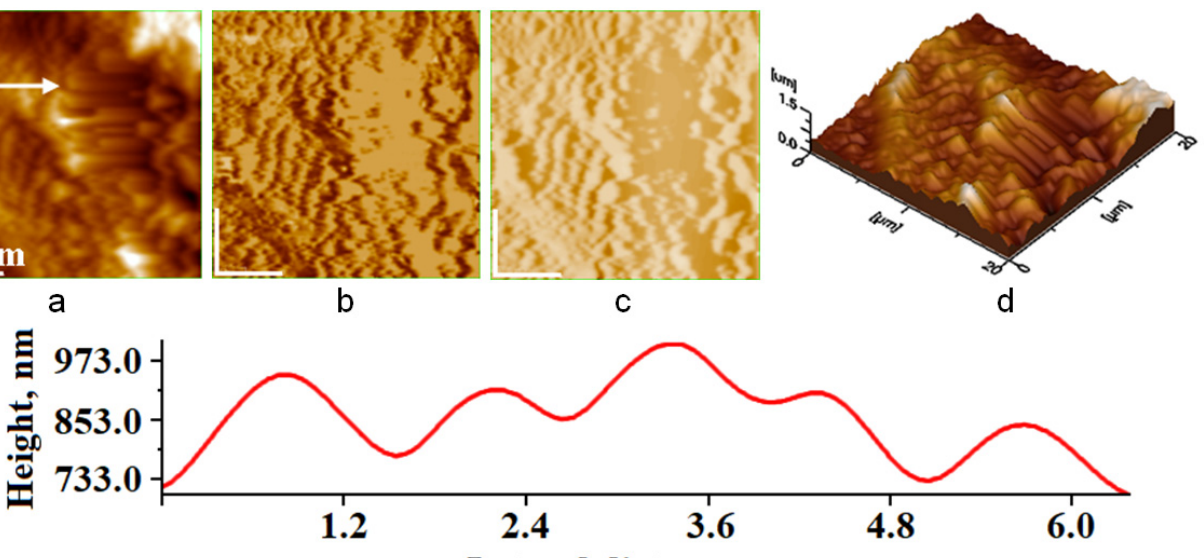

Lateral distance, $\mu \mathrm{m}$

e

Figure 2. AFM images of Ti surface after the cold pressing: a) two-dimensional (2D) topographic image, b) phase image, c) amplitude image, d) tridimensional (3D) image, and e) profile along the arrow in panel (a). Scanned area $20 \mu \mathrm{m}$ x 20 m; Ra 265 nm; Rq (RMS: root mean square) $330 \mathrm{~nm}$. by AFM.

The Ti surface changing towards the preparation steps was investigated

The Ti rod after cold pressing presents an irregular surface due to the metal interaction with press dies, Figure 2. It looks like the micro-structural Ti grains were pinched, fact which increases the Ra roughness from $141 \mathrm{~nm}$ as received to $265 \mathrm{~nm}$. This Ti surface is not suitable for biomimetic coatings. This is sustained by the significant irregularities reveled by phase and amplitude images, Figures $2 \mathrm{~b}$ and $2 \mathrm{c}$. The lack of proper Ti surface is more evident in the tridimensional (3D) image, Figure $2 d$, in good agreement with the cross profile shown in Figure $2 \mathrm{e}$.

Therefore, a texture was induced by grinding with P500 abrasive paper and the Ti surface changes are observed in Figure $3 a$. The irregularities were removed, and a ditch structure was formed. Some fine debris particles were observed on the surface and were removed by ultrasound cleaning. The surface uniformity is clearly sustained by the phase and amplitude images, Figure $3 b$ and $3 c$. The surface texturing is more evident in Figure $3 d$. The ditch structure formation on the surface is sustained by the profile in Figure $3 e$. Some irregularities still appear on the edges of ditches, which require an acid treatment. 


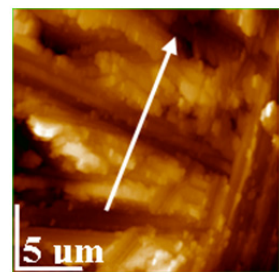

a

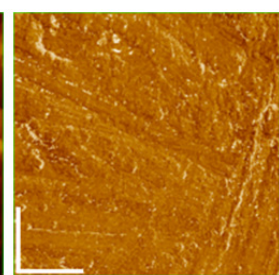

b

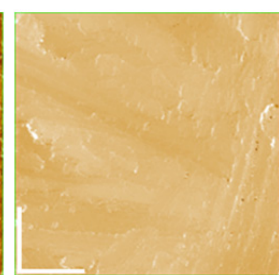

C

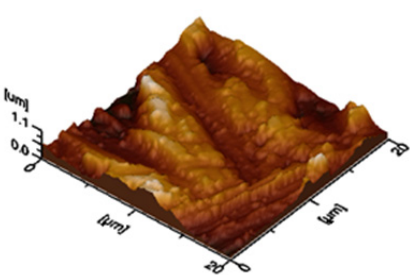

d

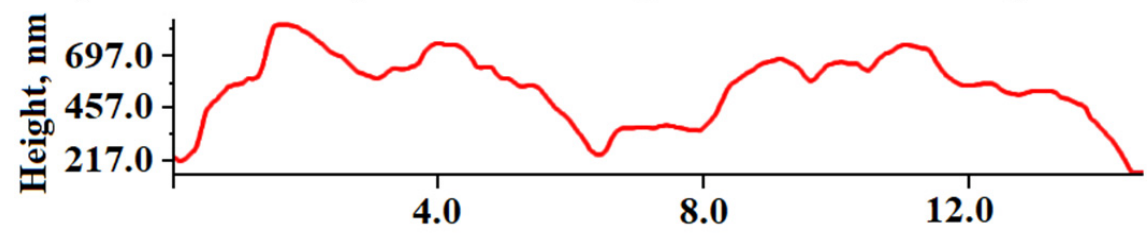

Lateral distance, $\mu \mathrm{m}$

e

Figure 3. AFM images of Ti grinded with P500: a) topographic image, b) phase image, c) amplitude image, d) 3D image, and e) profile along the arrow in panel (a). Scanned area $20 \mu \mathrm{m}$ x $20 \mu \mathrm{m}$; Ra 154 nm; Rq 186 nm.

Finally, the Ti rod surface was chemically activated with orthophosphoric acid and presents well-formed ditches with sharp edges which are perfectly cleaned and degreased, Figure $4 a$. The proper preparation of the Ti surface is also proven by the phase image, Figure 4b.

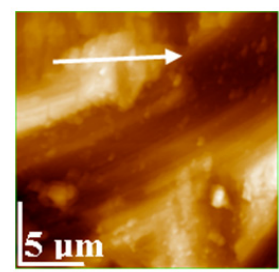

a

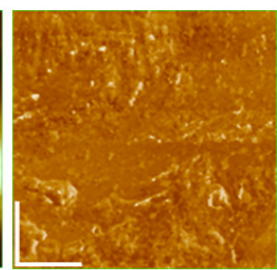

b

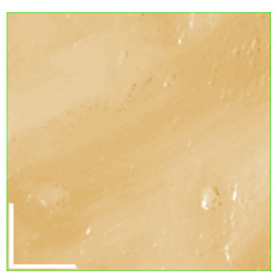

C
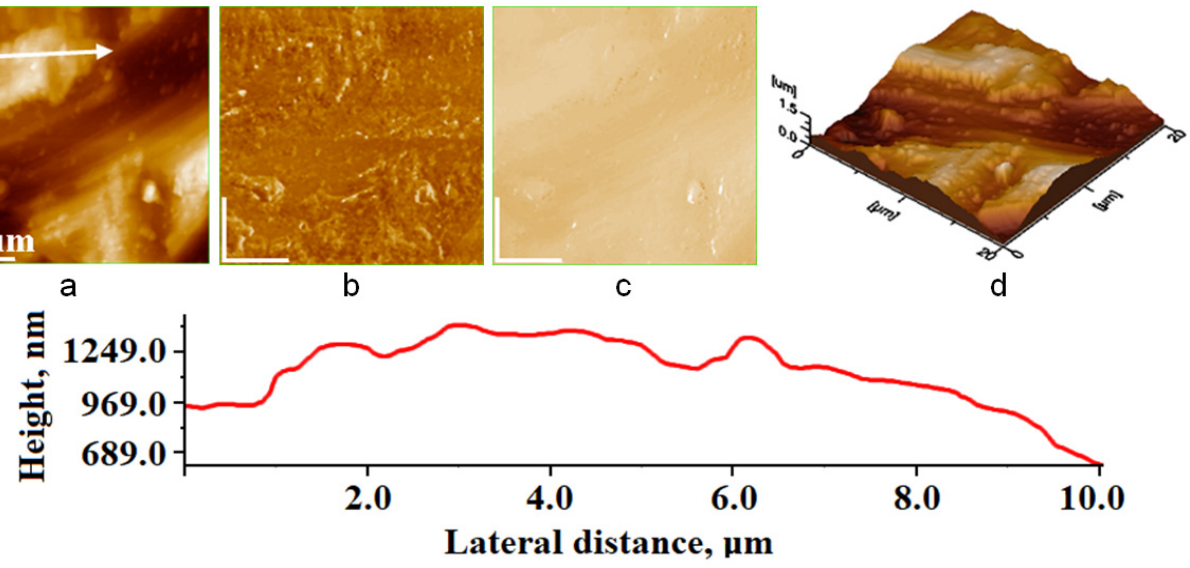

e

Figure 4. AFM images of Ti grinded with P500 and etched with ortho-phosphoric acid: a) topographic image, b) phase image, c) amplitude image, d) 3D image, and e) profile along the arrow in panel (a). Scanned area $20 \mu \mathrm{m} \times 20 \mu \mathrm{m}$; Ra $176 \mathrm{~nm} ; \mathrm{Rq} 218 \mathrm{~nm}$. 
REKA BALINT, IOAN PETEAN, PETRE T. FRANGOPOL, AURORA MOCANU, GEORGE ARGHIR, SORIN RIGA, GHEORGHE TOMOAIA, OSSI HOROVITZ, MARIA TOMOAIA-COTISEL

Amplitude image in Figure 4c shows that the Ti surface is free of defects and is optimal for coating with composite material. Overall, the AFM investigation proves that this surface morphology is suitable for biomimetic coating. The less viscous dispersion 1 will flow easily into the ditches and fits the edges and leads to a strong attachment of the composite to the $\mathrm{Ti}$ surface after drying.

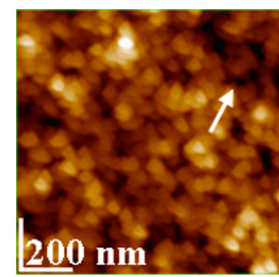

a

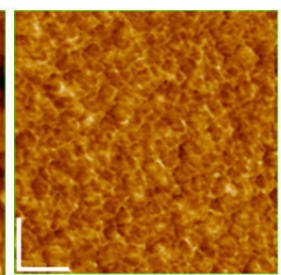

b

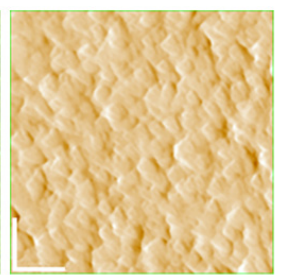

C

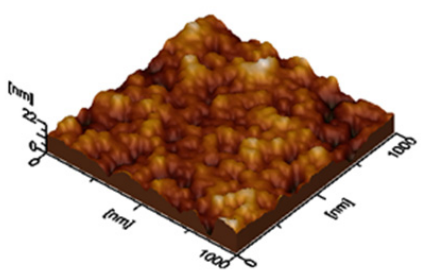

d

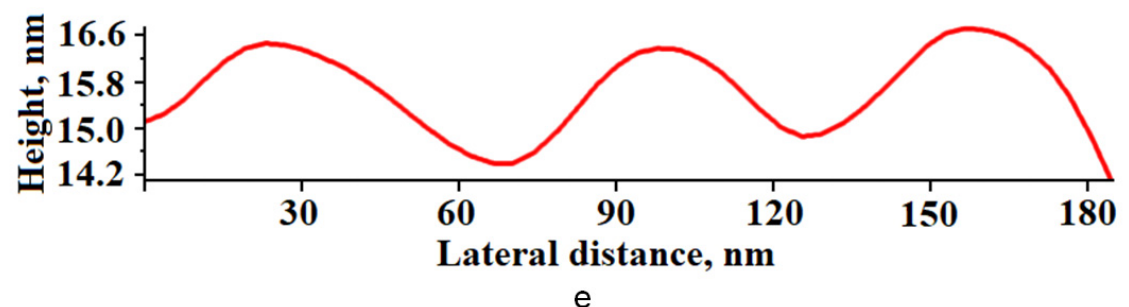

Figure 5. AFM images of HAPc-6\%COL (core-shell) nanoparticles: a) topographic image, b) phase image, c) amplitude image, d) 3D image, and e) profile along the arrow in panel (a). Scanned area $1 \mu \mathrm{m} \times 1 \mu \mathrm{m}$; Ra $2.29 \mathrm{~nm}$; Rq $2.89 \mathrm{~nm}$.

The major component in our coating material is the freeze dried ms-HAP/6\%COL core-shell NPs which provide both biomimetic components of the coating, namely nanostructured ms-HAP particles, noted also $\mathrm{HAPc}=\mathrm{HAP}-1.5 \mathrm{wt} \% \mathrm{Mg}-0.2 \mathrm{wt} \% \mathrm{Zn}-0.2 \mathrm{wt} \% \mathrm{Si}$, functionalized with $6 \%$ collagen. The HAPc NPs were investigated by AFM, Figure 5, and appear well individualized particles adsorbed on the Ti surface (Fig. 5a-d). The HAPc NPs have rounded shape and a diameter of about $50 \mathrm{~nm}$ as observed in profile, Figure $5 \mathrm{e}$. Usually HAPc nanoparticles have around $40 \mathrm{~nm}$, but the presence of collagen on HAPc NPs increases their diameter.

Collagen capping of HAPc nanoparticles is more evident in the phase image, Figure $5 \mathrm{~b}$, where the coating pellicle is observed in yellow nuance meanwhile HAPc nanoparticles appears in brown nuance. The adsorbed HAPc-6\%COL film is smooth and uniform having a Ra of about $2.29 \mathrm{~nm}$ and $\mathrm{Rq}$ of about $2.89 \mathrm{~nm}$, in good agreement with tridimensional observation, in Figure 5d, and cross profile in Figure 5e. 
The XRD patterns in Figure 6 reveal less intense and broadened peaks due to the fine diameter of HAPc particles and to the presence of collagen corona. The crystallite size determined with Scherrer formula shows a diameter of about $42 \mathrm{~nm}$. It is a good correlation with the AFM observation proving that the observed nanoparticles have a crystalline core of about $40 \mathrm{~nm}$ which is coated with collagen corona.

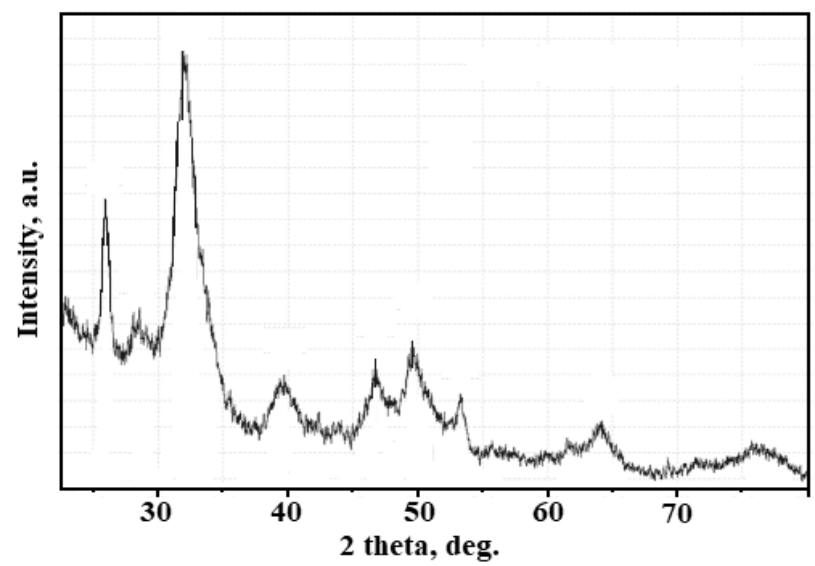

Figure 6. XRD pattern for $\mathrm{HAPc}-6 \% \mathrm{COL}$ (core-shell) nanoparticles.

The nanostructure in Figure 5 is usual for a lyophilized powder but far away from a biomimetic coating. The biomimetic structure needs to be promoted. Collagen is the thread that holds together the living bodies. Therefore, its natural forms represent guidance for the biomimetic patterning. The collagen structure involved in hard tissue is of great interest for present paper. Literature results show that bones contain collagen type I fibers having rounded section and diameters varying from fibrils (e.g. $67 \mathrm{~nm}$ ) to large formations of about $10 \mu \mathrm{m}$ strongly mineralized with HAP [44-49].

As a first step to establish biomimetic structure, a simpler task was performed. Collagen, as the one in HAPc-6\%COL NPs, was dispersed at alkaline $\mathrm{pH}$ and self-assembled on the solid substrate (e.g. three successive layers transferred by vertical adsorption onto glass) to observe the natural, biologic assemblies of COL fibers. The resulted structures were observed by AFM at a scan size of $20 \mu \mathrm{m} \times 20 \mu \mathrm{m}$, in Figure 7 .

Clearly, collagen self-assembled from alkaline dispersion onto solid substrate produces a biomimetic display like the one required for bone regeneration [44]. A $10 \mu \mathrm{m}$ diameter pore is observed in the center of the image in Figure 7a. A denser area of interconnected collagen fibers is observed in the left side of the pore. A significant number of collagen fibers begin from the dense area to the pore border. 
REKA BALINT, IOAN PETEAN, PETRE T. FRANGOPOL, AURORA MOCANU, GEORGE ARGHIR, SORIN RIGA, GHEORGHE TOMOAIA, OSSI HOROVITZ, MARIA TOMOAIA-COTISEL

The inside area of the pores is visibly distinct in phase image having brown nuance, Figure $7 \mathrm{~b}$. The network of COL fibers is clearly observed in the amplitude image, Figure 7c. These collagen fibers have similar shape and size with the natural collagen generated by osteoblast cells [44, 45]. The profile takes over three almost parallel COL fibers, Figure $7 \mathrm{e}$, and reveals a diameter of fibers of about $600 \mathrm{~nm}$, being in good agreement with published data.

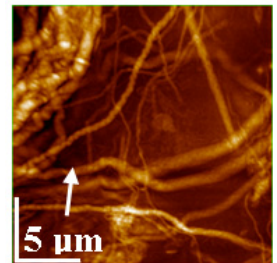

a

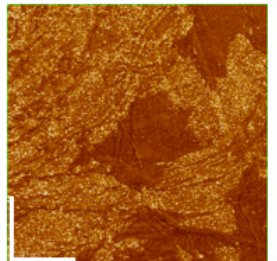

b

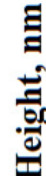

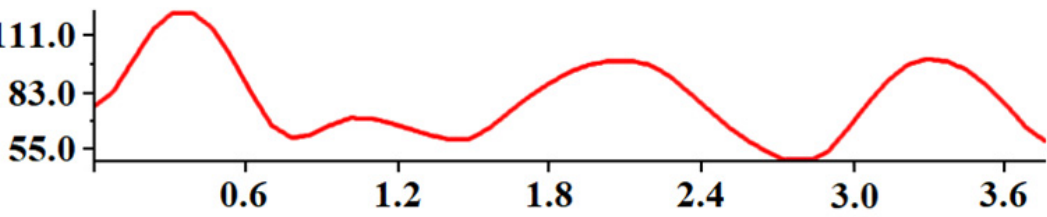

Lateral distance, $\mu \mathrm{m}$

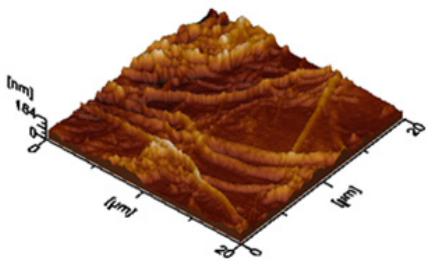

d

e

Figure 7. AFM images of collagen fibers self-assembled on glass from $\mathrm{COL}$ alkaline dispersion: a) topographic image, b) phase image, c) amplitude image, d) 3D image, and e) profile along the arrow in panel (a). Scanned area $20 \mu \mathrm{m} \times 20 \mu \mathrm{m}$; Ra $22.2 \mathrm{~nm}$; Rq $27.3 \mathrm{~nm}$.

The presence of HAPc is required as mineralizer of network of collagen fibers to generate biomimetic bone like structure. The HAPc$6 \% \mathrm{COL}$ nanoparticles contain the natural ratio between HAP and COL and it is expected to generate the biomimetic structure during the drying of the applied layers on the Ti surface.

Porosity is an important requirement for a bone biomimetic structure to assure enough space for osteoblasts adhesion and proliferation $[44,45]$. The acetone addition (beside the main role as fluidizer) in the first dispersion used for coating presents the benefit of significant pore generation during evaporation of HAPc-6\%COL@PLA. The significant pore creation in the first three layers is important because the second dispersion used for coatings covers with composite the bottom of pores preventing $\mathrm{Ti}$ contact with osteoblasts. The interlocking of the second dispersion used for coating into these pores of the basal layers results in a rough surface of the coating. 
Therefore, the pores network is a useful structure as observed in Figure 8, for HAPc-6\%COL@PLA coating on Ti implant. These pores are of submicron size and are lastly generate by the slower evaporation of dichloromethane (DCM) under drying process of bio-composite. Such morphology could be useful to facilitate the adhesion of osteoblasts to the coating surface on $\mathrm{Ti}$ implant.
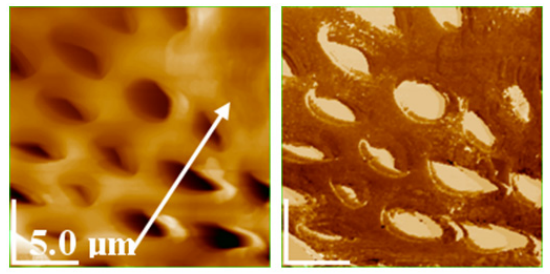

b

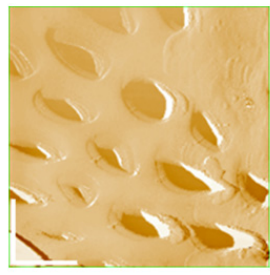

C

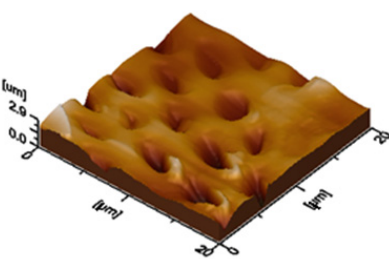

d

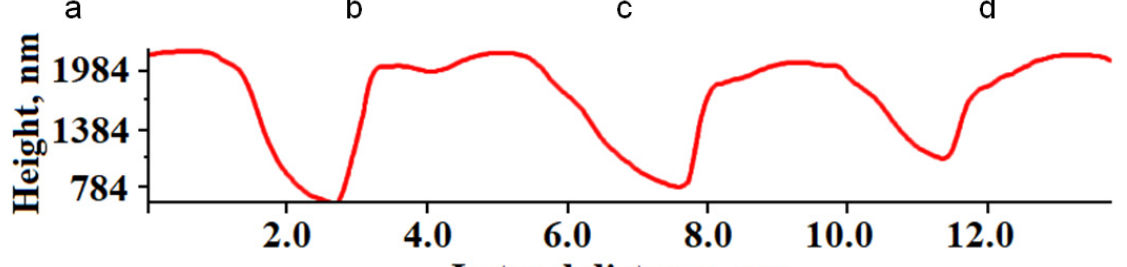

\section{Lateral distance, $\mu \mathrm{m}$}

e

Figure 8. AFM images of pores network on HAPc-6\%COL@PLA surface: a) topographic image, b) phase image, c) amplitude image, d) 3D image, and e) profile along the arrow in panel (a). Scanned area $20 \mu \mathrm{m} \times 20 \mu \mathrm{m}$; Ra 289 nm; Rq $360 \mathrm{~nm}$.

A network with relative parallel pores lines is observed at area of $20 \mu \mathrm{m} \times 20 \mu \mathrm{m}$ in Figure 8a. Also, Figures 8b, 6c and 8d show that the pores are distinctly evidenced.

The roughness of the composite HAPc-6\%COL@PLA surface is relatively high. The nano-topography proves the HAPc-6\%COL@PLA composite to be a biomimetic structure which can be a promoter for the osteoblast's adhesion on the surface.

Therefore, a closer look to the pores is required. Figure 9 indicates the constitution of a well-developed pore having a diameter of about $2.5 \mu \mathrm{m}$. The material around the pore is dense and compact showing an optimum bonding of ms-HAP crystals with COL and PLA, as observed in phase image, Figure 9b, and in amplitude image, Figure 9c. The intermediary layers are still visible on the pore wall in the 3D image, Figure 9d. The pore profile, Figure 9e, has a parabolic conformation with flat bottom. The depth of the pore is about $1 \mu \mathrm{m}$. 
REKA BALINT, IOAN PETEAN, PETRE T. FRANGOPOL, AURORA MOCANU, GEORGE ARGHIR, SORIN RIGA, GHEORGHE TOMOAIA, OSSI HOROVITZ, MARIA TOMOAIA-COTISEL

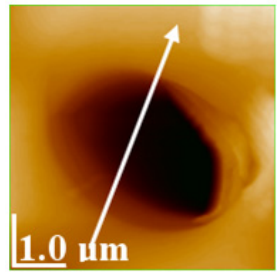

a

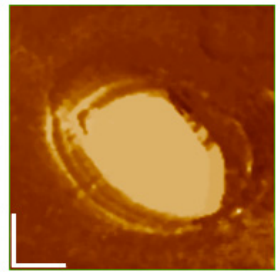

b

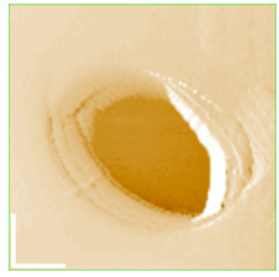

C

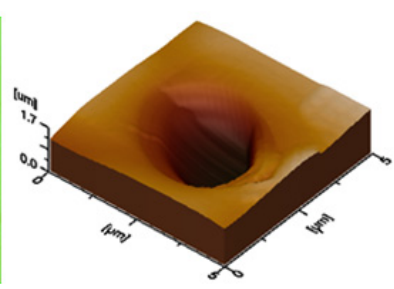

d

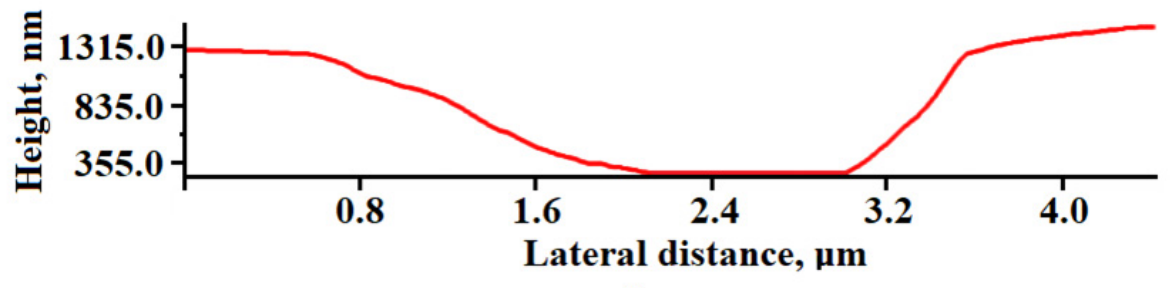

e

Figure 9. AFM images of a single pore on HAPc-6\%COL@PLA composite surface: a) topographic image, b) phase image, c) amplitude image, d) 3D image, and e) profile along the arrow in panel (a). Scanned area $5 \mu \mathrm{m} \times 5 \mu \mathrm{m}$;

Ra $342 \mathrm{~nm}$; Rq $434 \mathrm{~nm}$.

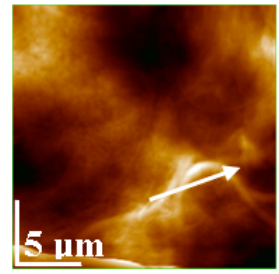

a

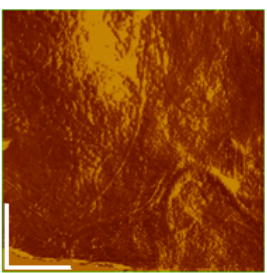

b

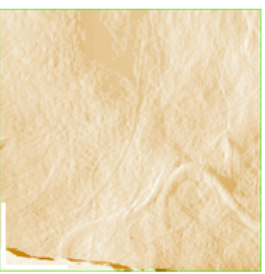

C

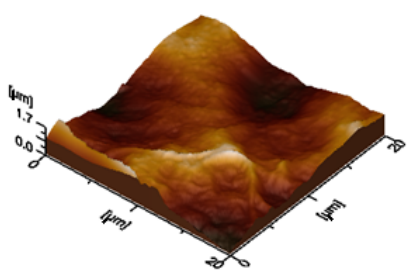

d

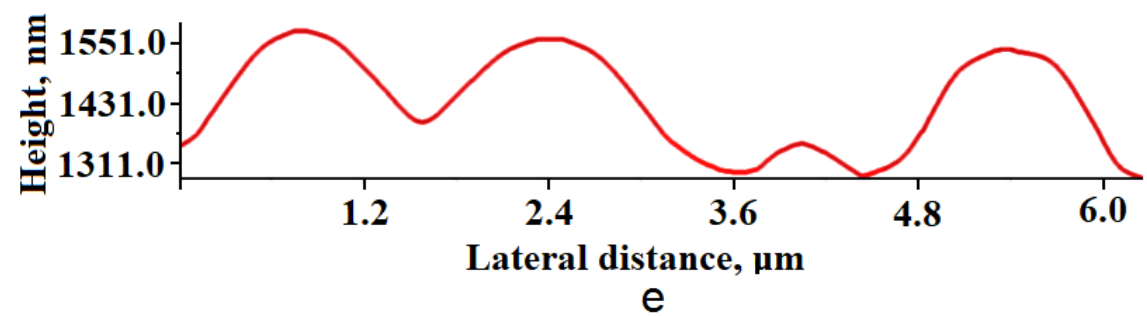

Fig. 10. AFM images of the surface of HAPc-6\%COL@PLA/COL composite selfassembled on Ti implant: a) topographic image, b) phase image, c) amplitude image, d) 3D image, and e) profile along the arrow in panel (a). Scanned area $20 \mu \mathrm{m} \times 20 \mu \mathrm{m}$; Ra 256 nm; Rq 304 nm. 
The morphology of the HAPc-6\%COL@PLA/COL composite surface is illustrated in AFM images, Figure 10, at scanned area of $20 \mu \mathrm{m} \times 20 \mu \mathrm{m}$. The formation of COL fibers on the surface of this biomimetic structure is revealed particularly in Figure $10 \mathrm{a}, 10 \mathrm{c}$ and $10 \mathrm{e}$. The porosity of this biomimetic HAPc-6\%COL@PLA/COL surface is also high. The surface roughness of the HAPc-6\%COL@PLA/COL composite is smaller than for the HAPc6\%COL@PLA composite structure. The surface roughness can be controlled in the preparation process of all this coating.

A central feature of this HAPc-6\%COL@PLA/COL surface is observed in Figure 11 at a scanned area of $5 \mu \mathrm{m} \times 5 \mu \mathrm{m}$. Surface topography reveals a divergent bunch of collagen fibers which reach the surface top on the left side of the image and spreads radially in the upper right side of the image. The COL fibers are well developed being distinctly observed in phase and amplitude images, Figures $11 \mathrm{~b}$ and $11 \mathrm{c}$, and very well horizontally attached on the surface as observed in 3D image in Figure $11 \mathrm{~d}$. A rounded profile of the collagen fibers with diameter varying from about $200 \mu \mathrm{m}$ to $400 \mu \mathrm{m}$ is given in Figure 11e. The COL fibers formation might appear also inside of the composite and this aspect cannot be ruled out.

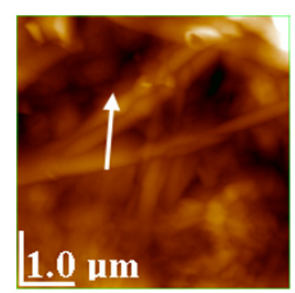

a

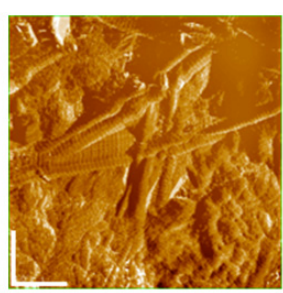

b

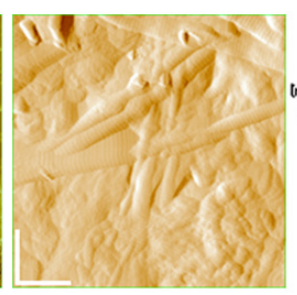

C

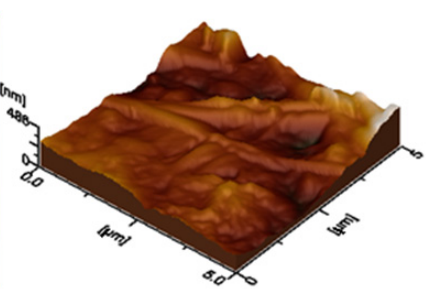

d

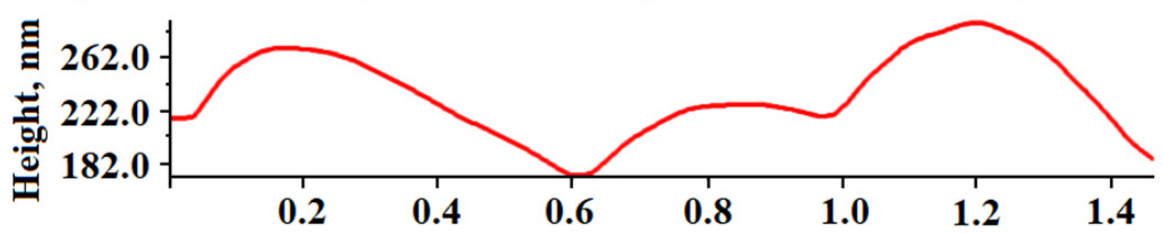

Lateral distance, $\mu \mathrm{m}$

e

Figure 11. AFM images of the HAPc-6\%COL@PLA/COL coating on Ti implant:

a) topographic image, b) phase image, c) amplitude image, d) 3D image,

e) profile along the arrow in panel (a). Scanned area $5 \mu \mathrm{m} \times 5 \mu \mathrm{m}$;

Ra $51.0 \mathrm{~nm} ; \mathrm{Rq} 65.4 \mathrm{~nm}$.

Further, Figure 12 illustrates a bunch of three collagen fibers, with diameter ranges from 90 to $300 \mathrm{~nm}$. The tropocollagen rings of the COL fibers are visible at the highest magnification of scanned area of $1 \mu \mathrm{m} \times 1 \mu \mathrm{m}$, in all 
REKA BALINT, IOAN PETEAN, PETRE T. FRANGOPOL, AURORA MOCANU, GEORGE ARGHIR, SORIN RIGA, GHEORGHE TOMOAIA, OSSI HOROVITZ, MARIA TOMOAIA-COTISEL

Figures $12 \mathrm{a}-12 \mathrm{~d}$. The tropocollagen rings are perfectly visible in the topographic image, Figure 12a, and their periodicity of about $67 \mathrm{~nm}$ is observed in the profile, given in Figure 12e.

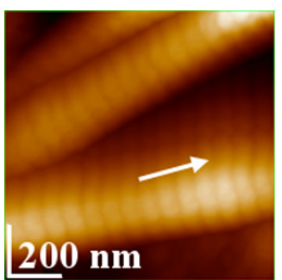

a

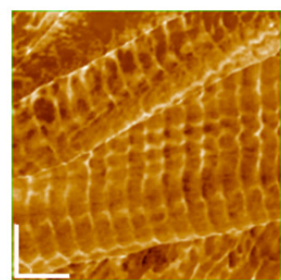

b

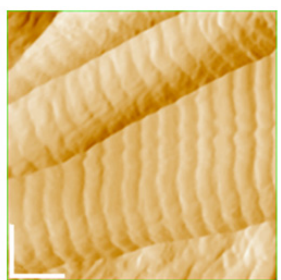

C

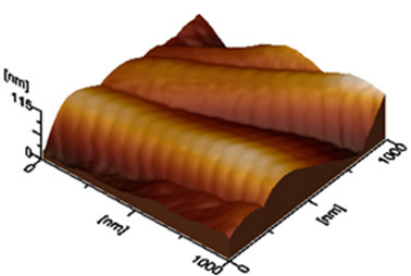

d

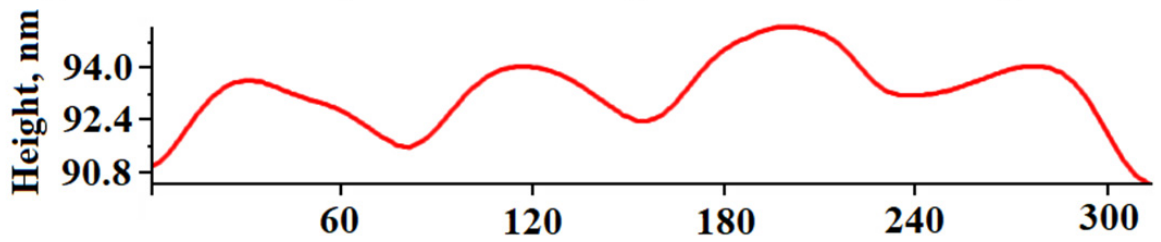

Lateral distance, $\mathbf{n m}$

e

Figure 12. AFM images of the HAPc-6\%COL@PLA/COL coating on Ti implant:

a) topographic image, b) phase image, c) amplitude image, d) 3D image, and e) profile along the arrow in panel (a). Scanned area $1 \mu \mathrm{m} \times 1 \mu \mathrm{m}$;

$\mathrm{Ra} 16.2 \mathrm{~nm}$; Rq $18.2 \mathrm{~nm}$.

Certainly, collagen fibers network formation on the HAPc-6\%COL@PLA/COL composite surface assures the major transformation from a simple nano-composite material to a biomimetic biocomposite structure, carrying COL branching bundles.

AFM probing the HAPc-6\%COL@PLA/COL surface reveals collagen fibers self-assembled on the surface of bio-composite. Furthermore, Figure 13 illustrates another feature, namely a bunch of two collagen fibers, perpendicularly oriented to each other.

The characteristics of COL fibers visualized in Figure 13 are comparable with those given in Figure 12. They adhere on the surface of biomimetic composite increasing the biocompatibility of whole coating surface on Ti implant.

The topography, Figure 13a, evidences a collagen fiber with diameter of about $400 \mathrm{~nm}$ (Figure 13e). The structural periodicity is better observed in Figures 13a, 13b, 13d and 13f. Profiles in Figure 13e evidence the fibers diameter and the periodicity of rings on the COL fiber, Figure 13f, which are in good agreement with related data [32, 44]. 


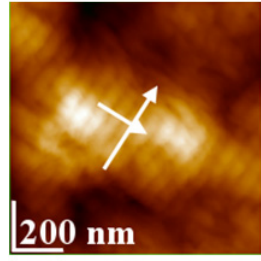

a

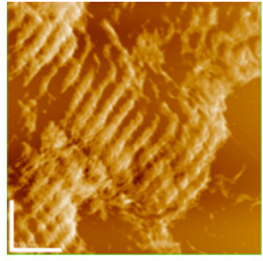

b

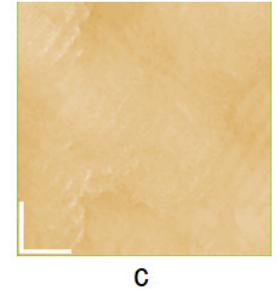

C
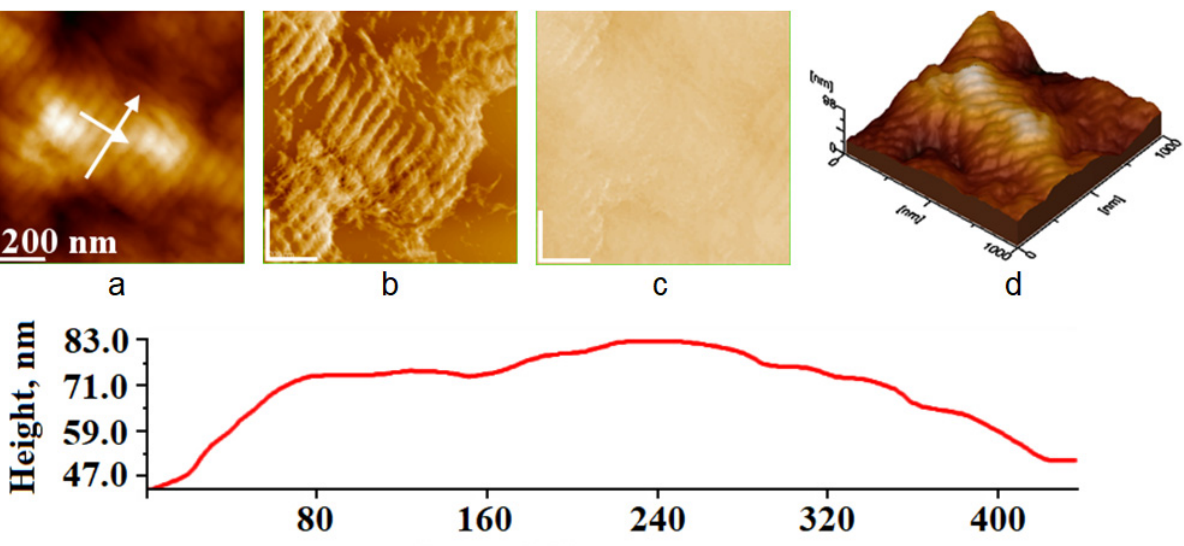

Lateral distance, $\mathbf{n m}$

e

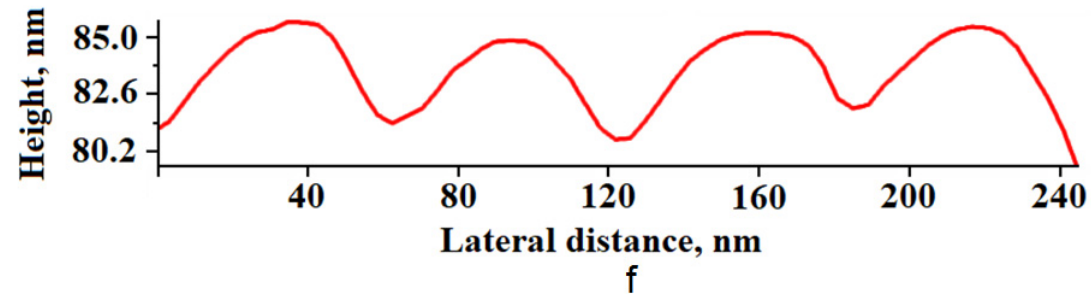

Figure 13. AFM images of the HAPc-6\%COL@PLA/COL biomimetic coating on Ti implant, view at highest magnification: a) topographic image, b) phase image,

c) amplitude image, d) 3D image; e) the profile along the arrow in panel (a, perpendicular on the axis of $\mathrm{COL}$ fiber); f) the profile along the arrow in panel (a, on the COL fiber axis). Scanned area $1 \mu \mathrm{m}$ x $1 \mu \mathrm{m}$; Ra $15.1 \mathrm{~nm}$; Rq $18.3 \mathrm{~nm}$.

In this investigation, the fibrillary structure of type 1 collagen has been revealed in detail, Figures 12 and 13. Thus, artificial collagen fibres display some properties of natural collagen fibrils and are now accessible using self-assembly technique, as shown in Figure 12. The understanding of the structural properties of native collagen fibres will guide the further development of fibrous biomimetic collagenous composites for biomedicine using nanotechnology.

This composite coating on $\mathrm{Ti}$ implant was recently investigated in vivo studies on femoral fracture rat model [32] and demonstrated a strong support for osteoblasts activity in the new bone formation and fracture healing. Also, recently in vivo study, this biomimetic composite coating on $\mathrm{Ti}$ implants showed a strong osseointegration with the native bone, in the same rat model. Our histological studies demonstrated the formation of trabecular bone and compact bone at 8 weeks after the implantation in the rat model [50]. 
REKA BALINT, IOAN PETEAN, PETRE T. FRANGOPOL, AURORA MOCANU, GEORGE ARGHIR, SORIN RIGA, GHEORGHE TOMOAIA, OSSI HOROVITZ, MARIA TOMOAIA-COTISEL

Our preliminary in vitro studies on these biomimetic composite structures used as scaffolds in stem cells culture displayed minimal degradation of scaffolds after one month, and all the scaffolds contained small amounts of woven bone and considerable amounts of osteoid in the process of mineralization. The ability of these biomimetic composite scaffolds to promote in vitro bone growth discloses a new property of these nanomaterials, named osteoinductivity, which might have a great impact in biomedical applications (unpublished results). Certainly, more studies are requested for clinical applications.

The surface roughness values, $\mathrm{Ra}$ (arithmetical roughness) and $\mathrm{Rq}$ (RMS: root mean square roughness), with their standard deviations are given in Table 1 for Ti surface before coating and in Table 2 for biomimetic coatings on Ti implants, for the same scanned area of $20 \mu \mathrm{m} \times 20 \mu \mathrm{m}$ measured by AFM. The standard deviation, SE, was calculated from at least 3 different areas scanned at $20 \mu \mathrm{m} \times 20 \mu \mathrm{m}$.

Table 1. The surface roughness, $\mathrm{Ra}$ and $\mathrm{Rq}$ (RMS),

of Ti implants before coatings, evaluated by AFM.

\begin{tabular}{|c|c|c|c|c|c|c|}
\hline Ti & \multicolumn{2}{|c|}{ Cold pressed } & \multicolumn{2}{c|}{$\begin{array}{c}\text { Ti } \\
\text { Grinded }\end{array}$} & $\begin{array}{c}\text { Ti } \\
\text { Grinded and etched with } \\
\text { acid }\end{array}$ \\
\hline Fig. & Ra \pm SD nm & $\begin{array}{c}\text { RMS } \pm S D \\
\mathrm{~nm}\end{array}$ & Ra \pm SD nm & $\begin{array}{c}\text { RMS } \pm S D \\
n m\end{array}$ & Ra $\pm S D$ nm & $\begin{array}{c}\text { RMS } \pm S D \\
n m\end{array}$ \\
\hline 2 & $265 \pm 25$ & $330 \pm 30$ & - & - & - & - \\
\hline 3 & - & - & $154 \pm 17$ & $186 \pm 19$ & - & - \\
\hline 4 & - & - & - & - & $176 \pm 18$ & $218 \pm 20$ \\
\hline
\end{tabular}

Table 2. The surface roughness, $\mathrm{Ra}$ and $\mathrm{Rq}$ (RMS), of biomimetic coatings on Ti implants measured by AFM.

\begin{tabular}{|c|c|c|c|c|}
\hline Composite & \multicolumn{2}{|c|}{ HAPc-6\%COL@PLA } & \multicolumn{2}{|c|}{ HAPc-6\%COL@PLA/COL } \\
\hline Fig. & $\begin{array}{c}\text { Ra } \pm \text { SD } \\
\mathrm{nm}\end{array}$ & RMS \pm SD nm & $\begin{array}{c}\text { Ra } \pm S D \\
\mathrm{~nm}\end{array}$ & $\begin{array}{c}\text { RMS } \pm \text { SD } \\
\mathrm{nm}\end{array}$ \\
\hline 8 & $289 \pm 24$ & $360 \pm 27$ & - & - \\
\hline 10 & - & - & $256 \pm 15$ & $304 \pm 26$ \\
\hline
\end{tabular}

$\mathrm{Ra}$ and $\mathrm{Rq}$ values were processed with Microcal Origin 6.0 analysis soft (Microcal Software Inc., Northampton M.A., USA) providing the standard deviation display. The resulted plots are presented in Figure 14. 


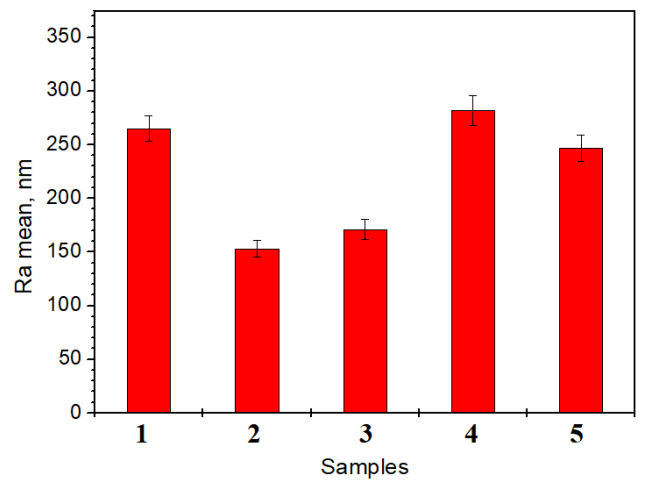

a

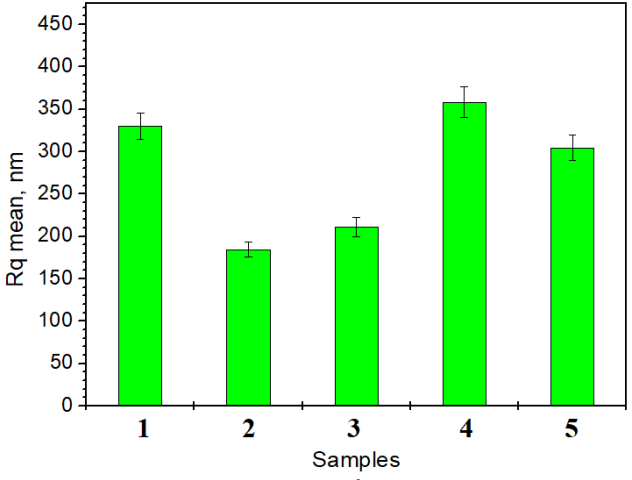

b

Figure 14. Mean roughness $\mathrm{Ra}(\mathrm{a})$ and $\mathrm{Rq}(\mathrm{RMS}, \mathrm{b})$ for $\mathrm{Ti}$ surface before coating:sample 1 (Ti, after the cold pressing); 2 (Ti, grinded with P500); 3 (Ti, grinded with P500 and etched with ortho-phosphoric acid) and after coating: 4 (Ti, sample 3 coated with HAPc-6\%COL@PLA composite); 5 (Ti, sample 3 coated with HAPc-6\%COL@PLA/COL biomimetic structure); all values estimated at scanned area of $20 \mu \mathrm{m} \times 20 \mu \mathrm{m}$; all values are statistically significant at $p<0.05$.

Both $\mathrm{Ra}$ (Figure 14a) and Rq (Figure 14b) values show the same trend during the processes developed in current study. Titanium implant samples 2-4 have an increased roughness due to the Ti surface treatment. The porosity formed in the HAPc- $6 \%$ COL@PLA coating on Ti implant leads to a strong increasing of surface roughness. The surface roughness is very well exemplified on the two-dimensional topographic images. The collagen layer added to the coating, resulted in HAPc-6\%COL@PLA/COL biomimetic composite coating, and leads to a sensitive decrease of the surface roughness due to some pore occlusion with collagen fibers. All samples have a controlled surface roughness, which can easily be modified as requested by the clinical applications; all the surface roughness values are statistically significant different at $p<0.05$.

\section{CONCLUSIONS}

AFM is a powerful tool for investigation of the biomimetic composite coating on the titanium surface of implants. It proves that the collagen amount in the nano-composite material can reticulate. The AFM images revealed a biomimetic network of collagen fibers like the one in natural bone formed on the surface of nano-composite layers. The nano-topography and surface roughness are evidenced by AFM microscopy in the coating layers 
REKA BALINT, IOAN PETEAN, PETRE T. FRANGOPOL, AURORA MOCANU, GEORGE ARGHIR, SORIN RIGA, GHEORGHE TOMOAIA, OSSI HOROVITZ, MARIA TOMOAIA-COTISEL

on Ti implants and are suitable for osteoblasts attachment to the surface increasing the cells viability. Adding an extra layer of pure collagen could be a facile enhancer of osteoblasts activity to generate new bone on the revealed biomimetic structures.

\section{EXPERIMENTAL SECTION}

The titanium rods were purchased from Goodfellow Cambridge Limited, Huntingdon, England and machined in our laboratory to the desired surface condition. Materials for the coating are: polylactic acid PLA 3051 D, obtained from Nature Works, Minnetonka, MN, USA; dichloromethane high purity (DCM), acetone $\geq 99.5 \%$, type $1 \mathrm{COL}$ from bovine Achilles tendon lyophilized powder, and an $85 \%$ phosphoric acid aqueous solution, $99.99 \%$ purity, all purchased from Sigma-Aldrich (St Louis, MO, USA).

Titanium samples preparation: The rounded titanium rods were flattened with a $20 \mathrm{TF}$ hydraulic press to obtain a rectangular section of 3 $\mathrm{mm}$ width and $1.5 \mathrm{~mm}$ thick and cut into sticks with a $20 \mathrm{~mm}$ length. The plan parallel shape of the sticks is required for a proper AFM investigation. Both sides of the sticks were grinded with P500 abrasive paper for 10 minutes to obtain a proper texture of the active surface. The grinding debris was removed by intense washing with bi-distilled water, followed by an ultrasound cleaning. An ultrasound device Sonic Vibra-Cell VCX 750 Watt was used for this purpose. After cleaning the rods were chemically activated for 30 min with orto-phosphoric acid to obtain a perfectly clean and degreased surface.

Preparation of the coating dispersions: There were prepared two dispersions for the sticks coating. The first one is more fluid to assure a strong bonding to the titanium surface and to become the resistant layers. Second dispersion is more viscous to assure a better structuring among HAP and $\mathrm{COL}$ to promote the biomimetic aspect of the composite. The granular matter of the composite is a complex HAP based powder functionalized with $6 \%$ collagen synthesized by a wet precipitation method described in our previous papers $[37,39]$. This powder is further noted as HAPc-6\%COL. PLA solution was prepared by PLA dissolution in dichloromethane (DCM). PLA was dissolved in DCM under strong magnetic agitation in ratio of $4.8 \%$ (e.g. $1 \mathrm{~g}$ of PLA in $15 \mathrm{ml}$ of pure DCM). Two dispersions were prepared when PLA was completely dissolved into DCM. The first contains $76 \%$ HAPc- $6 \% \mathrm{COL}$ and $24 \%$ PLA solution. The fluidity of this dispersion is enhanced by adding acetone. The second dispersion contains $71 \%$ HAPc-6\%COL and $29 \%$ PLA solution. 
Coating: The titanium surface prepared as described was coated with successive layers using dip coating method. Three successive layers of dispersion 1 were transferred: 30 seconds of adsorption followed by a slow retraction of sample from dispersion tank and followed by 10 minutes of natural drying. Afterwards, three successive layers of dispersion 2 were transferred in the same condition. It results the titanium sample coated with composite material in which we expect to develop biomimetic structure (further marked as HAPc-6\%COL@PLA). A similar sample was prepared, and a pure collagen layer was transferred via vertical adsorption 5 seconds from rich $\mathrm{COL}$ solution at $\mathrm{pH} 12$, resulting HAPc-6\%COL@PLA/COL biomimetic structure on Ti implant.

$X$ ray diffraction (XRD) was performed on a D8 ADVANCE X-ray diffractometer from Bruker AXS GmbH, Karlsruhe, Germany (Bragg-Brentano geometry) using $\mathrm{Cu} \mathrm{Ka}$ radiation. Diffraction peaks were indentified using Match 1.0 data base powered from Crystal Impact Co.

AFM microscopy was performed on a JSPM 4210 Scanning Probe Microscope, Jeol, Japan. The surface morphology and roughness were estimated as previously presented by us [51-56]. The images were scanned in tapping mode using NSC 15 Hard cantilevers produced by Micromesh Co, Estonia. The resonance frequency of the cantilever is about $325 \mathrm{kHz}$ and the force constant of $40 \mathrm{~N} / \mathrm{m}$. The obtained images were processed in the standard manner using the specific soft Win SPM2.0 Processing, Jeol, Japan.

Statistical analysis: For statistical analysis GraphPad Prism 6 for Windows was used. The values of surface roughness, $\mathrm{Ra}$ and $\mathrm{Rq}$ (RMS), were estimated as the mean value \pm standard deviation (SD). Statistical significance was identified using one-way ANOVA test followed by Tukey post-hoc test.

\section{ACKNOWLEDGMENTS}

This work was supported by grants of the Ministry of Research, Innovation and Digitization, CNCS/CCCDI-UEFISCDI, project number 186 and 481, within PNCDI III. 
REKA BALINT, IOAN PETEAN, PETRE T. FRANGOPOL, AURORA MOCANU, GEORGE ARGHIR, SORIN RIGA, GHEORGHE TOMOAIA, OSSI HOROVITZ, MARIA TOMOAIA-COTISEL

\section{REFERENCES}

1. R. Balint; G. A. Paltinean; Gh. Tomoaia; D. Oltean-Dan; A. Mocanu; M. Tomoaia-Cotisel; Ann. Ser. Biol. Sci., 2021, 10(1), 90 - 145, ISSN 2285 4177.

2. I. Cacciotti; Int J Appl Ceram Technol., 2019, 16(5), 1864-1884.

3. M.H. Santos; P. Valerio; A.M. Goes; M.F. Leite; L.G.D. Heneine; H.S. Mansur; Biomed. Mater., 2007, 2(2), 135-141.

4. I.V. Antoniac; A. Antoniac; E. Vasile; C. Tecu; M. Fosca; V. G. Yankova; J.V. Rau; Bioact. Mater., 2021, 6(10), 3383-3395.

5. I. Ullah; M. A. Siddiqui; S. K. Kolawole; H. Liu; J. Zhang; L. Ren; K. Yang; Ceram. Int., 2020, 46(10), 14448-14459.

6. T. Kumai; N. Yui; K. Yatabe; C. Sasaki; R. Fujii; M. Takenaga; H. Fujiya; H. Niki; K. Yudoh; Int. J. Nanomedicine., 2019, 14, 1283-1298.

7. H. Liu; M. Lin; X. Liu; Y. Zhang; Y. Luo; Y. Pang; H. Chen; D. Zhu; X. Zhong; S. Ma; Y. Zhao; Q. Yang; X. Zhang; Bioact. Mater., 2020, 5(4), 844-858.

8. T. G. Kim; S.-H. Park; H. J. Chung; D.-Y. Yang; T. G. Park; J. Mater. Chem., 2010, 20, 8927-8933.

9. P. Pan; X. Chen; K. Metavarayuth; J. Su; Q. Wang; Curr. Opin. Colloid Interface Sci., 2018, 35, 104-111.

10. Z. Wang; Y. Yan; T. Wan; Sci. Eng. Compos. Mater., 2012, 19(2), 177-182.

11. T. Albrektsson; B. Chrcanovic; M. Jacobsson; A. Wennerberg; JSM Dent Surg, 2017, 2(3), 1022, 1-6.

12. A. Cappella; H.H. de Boer; P. Cammilli; D. De Angelis; C. Messina; L M. Sconfienza; F. Sardanelli; C. Sforza; C. Cattaneo; Forensic Sci. Int., 2019, 302, 109909, 1-9.

13. E.N. L'Abbé; S.A. Symes; D.E. Raymond; D.H. Ubelaker; Forensic Sci. Int., 2019, 299, 187 - 189.

14. L.H. Li; H.W. Kim; S.H. Lee; Y.M. Kong; H.E. Kim; J. Biomed. Mater. Res, 2005, 73A (1), 48-54.

15. N.S. Manam; W.S.W. Harun; D.N.A. Shri; S.A.C. Ghani; T. Kurniawan; M.H. Ismail; M.H.I. Ibrahim; J Alloys. Compd., 2017, 701, 698-715.

16. R. Trindade; T. Albrektsson; P. Tengvall; A. Wennerberg; Clin Implant Dent Relat Res, 2017, 18(1), 192 -203.

17. D. van Steenberghe; Eur J Oral Implantol.; 2018, 11(Supp/1), S15 - S20.

18. A. Dziubinska; K. Majerski; E. Siemionek; Procedia Manuf., 2018, 15, 411-418.

19. S. Cicek; A. Karaca; I. Torun; M. S. Onses; B. Uzer; Mater. Today: Proc., 2019, 7(1), 389-393.

20. N. Madhumitha; R.K. Bharath; J. World Fed. Orthod., 2017, 6(4), 171-176.

21. K. Patka; R. Pokrowiecki; Adv. Eng. Mater., 2018, 20(5), 1700648, 1-18.

22. W. Chen; K. Xu; B. Tao; L. Dai; Y. Yu; C. Mu; X. Shen; Y. Hu; Y. He; K. Cai; Acta Biomater., 2018, 74, 489-504.

23. Y. Li; C. Wong; J. Xiong; P. Hodgson; C. Wen; J Dent Res, 2010, 89(5), 493497. 
BIOMIMETIC NANOCOMPOSITE STRUCTURES DESIGNED FOR COATING OF ORTHOPEDIC IMPLANTS: AFM INVESTIGATION

24. M. D. Shoulders; R.T. Raines; Annu. Rev. Biochem., 2009, 78, 929-958.

25. R.J. DeVolder; I.W. Kim; E.S. Kim; H. Kong; Tissue Eng. Part A, 2012, 18 (1516), 1642-1651.

26. H.W. Kim; Y.H. Koh; L.H. Li; S. Lee; H.E. Kim; Biomaterials, 2004, 25(13), 2533-2538.

27. L.A. Sena; M.C. Andrade; A.M. Rossi; G. Almeida Soares; J. Biomed. Mater. Res, 2002, 60(10), 1-7.

28. X. Cai; H. Follet; L. Peralta; M. Gardegaront; D. Farlay; R. Gauthier; B. Yu; E. Gineyts; C. Olivier; M. Langer; A. Gourrier; D. Mitton; F. Peyrin; Q. Grimal; P. Laugier; Acta Biomater., 2019, 90, 254-256.

29. F.A. Shah; S. Sayardoust; P. Thomsen; A. Palmquist; Bone, 2019, 127, 244249.

30. J. Wang; C. Liu; J. Bionic Eng., 2014, 11(4), 600-609.

31. S. Minardi; F. Taraballi; F.J. Cabrera; J. Van Eps; X. Wang; S.A. Gazze; J. S. Fernandez-Mourev; A. Tampieri; L. Francis; B.K. Weiner; E. Tasciotti; Mater. Today Bio., 2019, 2, 100005, 1-11.

32. D. Oltean-Dan; G.B. Dogaru; M. Tomoaia-Cotisel; D. Apostu; A. Mester; H.R.C. Benea; M.G. Paiusan; E.M. Jianu; A. Mocanu; R. Balint; C.O. Popa; C. Berce; G.I. Bodizs; A.M. Toader; Gh. Tomoaia; Int. J. Nanomed., 2019, 14, 57995816.

33. I. Izquierdo-Barba; L. Santos-Ruiz; J. Becerra; M.J. Feito; D. Fernandez-Villa; M.C. Serrano; I. Diaz-Guemes; B. Fernandes Tome; S. Enciso; F.M. Sanches Margallo; D. Monopoli; H. Alfonso; M.T. Portoles; D. Arcos; M. Vallet-Regi; Acta Biomater., 2019, 83, 456-466.

34. Gh. Tomoaia; L.B. Pop; I. Petean; M. Tomoaia-Cotisel; Mater. Plast., 2012, 49(1), 48-54.

35. C. Garbo; M. Sindilaru; A. Carlea; Gh. Tomoaia; V. Almasan; I. Petean; A. Mocanu; O. Horovitz; M. Tomoaia-Cotisel; Part. Sci. Technol., 2017, 35(1), 2937.

36. F. Goga; E. Forizs; A. Avram; A. Rotaru; A. Lucian; I. Petean; A. Mocanu; M. Tomoaia-Cotisel; Rev. Chim., 2017, 68(6), 1193-1200.

37. Gh. Tomoaia; O. Soritau; M. Tomoaia-Cotisel; L.B. Pop; A. Pop; A. Mocanu; O. Horovitz and L.D. Bobos; Powder Technol., 2013, 238, 99-107.

38. S. Rapuntean; P.T. Frangopol; I. Hodisan; Gh. Tomoaia; D. Oltean-Dan; A. Mocanu; C. Prejmerean; O. Soritau; L.Z. Racz; M. Tomoaia-Cotisel; Rev. Chim., 2018, 69(12), 3537-3544.

39. Gh. Tomoaia; A. Mocanu; I. Vida-Simiti; N. Jumate; L.D. Bobos; O. Soritau; M.Tomoaia-Cotisel; Mater. Sci. Eng. C, 2014, 37, 37-47.

40. A. Mocanu; G. Furtos; S. Rapuntean; O. Horovitz; C. Flore; C. Garbo; A. Danisteanu; Gh. Rapuntean; C. Prejmerean; M. Tomoaia-Cotisel; App. Surf. Sci., 2014, 298, 225-235.

41. P.T. Frangopol; A. Mocanu; V. Almasan; C. Garbo; R. Balint; G. Borodi; I. Bratu; O. Horovitz; M. Tomoaia-Cotisel; Rev. Roum. Chim., 2016, 61(4-5), 337-344. 
REKA BALINT, IOAN PETEAN, PETRE T. FRANGOPOL, AURORA MOCANU, GEORGE ARGHIR, SORIN RIGA, GHEORGHE TOMOAIA, OSSI HOROVITZ, MARIA TOMOAIA-COTISEL

42. C. Garbo; J. Locs; M. D’Este; G. Demazeau; A. Mocanu; C. Roman; O. Horovitz; M. Tomoaia-Cotisel; Int. J. Nanomed., 2020, 15, 1037-1058.

43. A. Mocanu; O. Cadar; P.T. Frangopol; I. Petean; Gh. Tomoaia; G.A. Paltinean; C.P. Racz; O. Horovitz; M. Tomoaia-Cotisel; R. Soc. Open Sci., 2021, 8(1), 201785, 1-25.

44. A.M. Ferreira; P. Gentile; V. Chiono; G. Ciardelli; Acta Biomater., 2012, 8(9), 3191-3200.

45. P. Fratzl; Collagen: Structure and Mechanics, an Introduction, of the chapter 1. In Book Collagen: Structure and Mechanics; P. Fratzl_Editor; Springer: Boston, MA, U.S., 2008; pp. 1-13. DOI: 10.1007/978-0-387-73906-9.

46. X. Chen; L. Zhou; H. Xu; M. Yamamoto; M. Shinoda; I. Tad; S. Minami; K. Urayama; H. Yamane; Int. J. Biol. Macromol., 2019, 135, 959-968.

47. K. Saini; D. Discher; N. Kumar; J Mech. Behav. Biomed., 2019, 91, 315-325.

48. V. Baranauskas; I. Garavello; Z. Jingguo; M. A. da Cruz-Hofling; Appl. Surf. Sci., 2005, 248(1-4), 492-498.

49. T. Kreller; F. Sahm; R. Bader; A.R. Boccaccini; A. Jonitz-Heincke; R. Detsch; Materials, 2021, 14, 3516, 1-18.

50. D. Oltean-Dan; P.T. Frangopol; R. Balint, Gh. Tomoaia; A. Mocanu; M. Tomoaia-Cotisel; Studia. Univ. Babes-Bolyai. Chem., 2021, 66(3), in print.

51. I. Petean; Gh. Tomoaia; O. Horovitz; A. Mocanu; M. Tomoaia-Cotisel; J. Optoelectron. Adv. M., 2008, 10(9), 2289-2292.

52. L. Barbu-Tudoran; Gh. Tomoaia; O. Horovitz; A. Mocanu; M. Tomoaia-Cotisel; J. Optoelectron. Adv. M., 2008, 10(9), 2293-2297.

53. P.T. Frangopol; D.A. Cadenhead; M. Tomoaia-Cotisel; A. Mocanu; Studia. Univ. Babes-Bolyai. Chem., 2009, 54(1), 23-35.

54. M. Tomoaia-Cotisel; A. Tomoaia-Cotisel; T. Yupsanis; Gh. Tomoaia; I. Balea; A. Mocanu; C.P. Racz; Rev. Roum. Chim, 2006, 51(12), 1181-1185.

55. M. Tomoaia-Cotisel; A. Mocanu; Rev. Chim. (Bucharest), 2008, 59(11), 12301233.

56. Gh. Tomoaia; O. Horovitz; A. Mocanu; A. Nita; A. Avram; C.P. Racz; O. Soritau; M. Cenariu; M. Tomoaia-Cotisel; Colloids Surf. B, 2015, 135, 726-734. 